\title{
Antiphospholipid antibodies and single nucleotide polymorphisms in patients with venous ulcer in the population of Latvia
}

Background: Chronic venous insufficiency (CVI) may lead to leg ulceration (CVI stage C6) (Nicolaides A.N. et al., 2000). Some authors published that genetic risk factors are observed more frequently in patients with CVI stage C6. Also, an increased level of anticardiolipin antibodies (ACA) is observed in patients with CVI stage $C 6$. CVI stage $C 6$ more frequently develops in $C V I$ stage $C 3$ patients with positive antiphospholipid antibodies (APA) when compared to CVI stage C3 patients without APA.

Objective: To identify the association of single nucleotide polymorphisms (SNPs) of genes F5 ( $r 56025)$ F2 (rs1799963), SELE (rs5361), SERPINC1 (rs2227589), FGG (rs20066865), CYP4V2 (rs13146272), F11 (rs2289252), GP6 (rs1613662) and APA antibodies with CVI stage in the population of Latvia.

Methods: The study group consisted of $188 \mathrm{CVI}$ patients. APA was detected in $89 \mathrm{CVI}$ patients. The diagnostics of CVI was based on clinical and duplex ultrasound data (Philips Sparq, 2012). APA was detected using ELISA assay (according to the manufacturer's protocol (Demeditec Diagnostics GmbH, Germany)). Statistical analysis was performed using Plink 1.06. Software and Fisher exact tests.

Results: Polymorphism of gene F11 (rs2289252) showed an association with CVI stage C6 (OR=1.81 $(p=0.024)$.

A statistically significant elevation of APA was observed in patients with CVI stage C6 when compared to patients with CVI stage $C 3(\mathrm{p}=0.05)$.

Conclusions: The polymorphism of gene F11 (rs2289252) and positive APA showed an association with CVI stage C6.

Keywords: single nucleotide polymorphisms • trophic ulcers $\bullet$ chronic venous insufficiency $•$ venous ulcer • antiphospholipid antibodies $•$ anticardiolipin $•$ antibodies $\bullet$ antiphospholipid $\bullet$ syndrome trophic ulcers

\section{Introduction}

CVI has high prevalence and is correlated with a significant socioeconomic impact in Western countries because of the cost of investigation, treatment and loss of working days [1]. CVI is present in $25 \%$ to $33 \%$ of female and 10 $20 \%$ in male adults [1]. CVI stage C6 is found in $0.3 \%$ of the adult population in Western countries [1,2]. In the Bonn Vein Study, 23\% of the population was found to have venous varices [3]. In the United Kingdom (UK), the life-time risk of development of CVI stage C6 is $1 \%$, and the annual cost of treatment is estimated at approximately, $\$ 1$ billion, which makes up $1 \%$ to $2 \%$ of total healthcare spending $[4,5]$. Similar figures are found in other European countries and in North America [4,5].
The main reason for CVI development is valvular damage and/or DVT $[1,6]$. Congenital factors, female gender, pregnancy, little physical activity, contraception, excess weight, age and family history of CVI also play an important role in the development of CVI $[7,8]$. DVT is not involved directly in CVI stage C6 formation, but it has been recognised as an important risk factor associated with it [9]. According to a recent study by Darvall et al. $75 \%$ of patients with CVI stage C6 show single or multiple genetic factors that predispose them to an increased incident of clinical and subclinical DVT $[10,11]$. Approximately $43 \%$ of CVI stage C6 individuals have had at least one previous clinically overt DVT episode [10,11]. Several studies have found that genetic risk factors such as mutations in factor V, prothrombin, antithrombin III,
Irina Kajuna*, Valda Staṇēviča \&

\section{Helēna Mikažāne}

Rīga Stradinš University, Baltic Vein Clinic (BVC), Latvia

*Author for correspondence:

irina.kajuna@gmail.com 
protein $\mathrm{C}$ and $\mathrm{S}$ genes is found more frequently in patients with CVI stage C6 (44-75\%) [12]. In the general population, the prothrombin 20210 A variant is found in $2 \%$ of individuals. In the patients with DVT the prothrombin $20210 \mathrm{~A}$ variants is found in approximately $6 \%$ of individuals and in the patients with CVI stage C6 up to $4 \%$ of individuals [10,13-15]. Factor V Leiden the mutant allele is found at a frequency of approximately $5 \%$ in Caucasian populations; the prevalence of this risk allele in patients with recognised DVT is as high as $30 \%$, whereas in the group of patients with CVI stage C6 it ranges from between 8 and 36\%, depending on the estimated population size $[2,10]$. It is important to characterize populations using molecular tools. The applications of molecular genetics have many important advantages [16], hence determination of gene polymorphism is important in different populations [17-19].

Some studies have shown that CVI stage C6 develops more frequently in patients with CVI stage C3 with positive APA [20,21]. The pathogenic mechanism of venous ulcer formation involves tissue oedema, hyperpigmentation, skin atrophy before ulcer development [2022]. Microlymphangiopathy, lymphatic vessel dilatation and capillary dilatation, elongation and microthrombotic occlusion are found at a microvascular level [20-22].

APA is a heterogeneous group of autoantibodies directed against phospholipid-binding plasma proteins (most commonly beta-2-glycoprotein (B2GP)) [23]. APA are also produced against proteins participating in the coagulation process - prothrombin, protein $\mathrm{C}$, protein $\mathrm{S}$ and others [24]. The causes of APA formation include infections and drugs [23]. Increased levels of ACA during infection are usually transient, and IgM antibodies are elevated more frequently than IgG [23].

\section{Materials and Methods}

The study group consisted of 188 patients with CVI stage C3-C6 (including 62 patients with CVI stage C6). AFA were detected in 89 CVI patients (fifty-three (53) patients had CVI stage C3 and 36 patients had CVI stage C6). The inclusion criteria for the study group: patient is 18 years of age or above, the patient is not mentally retarded, the patient is diagnosed with one of the following diseases - CVI, trophic ulcer, optional criterion - family history of DVT. The diagnostics were based on clinical and duplex ultrasound data (Philips Sparq, 2012).
The control group consisted of 188 individuals selected from the Genome database of the Latvian population (LGDB). Individuals with diagnoses I11 to I99 (according to ICD10) were not included in the control group. The case and control group were matched for sex, age and BMI. The control group characteristics: for CVI C3 patients control group 28 men and 98 women, average age $46.3 \pm 13.1$ years, BMI $27.2 \pm 4.6$; for CVI C6 patients control group 14 men and 48 women, average age $61.9 \pm 11.9$ years, BMI $30.2 \pm 5.7$. The adjustment for sex, age, BMI was performed to exclude the possible influence of these factors on association results, as the groups were closely matched, however, not identical and it was not possible to ensure matching of the groups in the stratification analysis.

DNA samples from white blood cells (WBC) were diluted using Freedom Evo robotic workstation (Tecan, Männedorf, Switzerland) with disposable filter tips into 372 wells of 380well PCR plates (28 ng per well), eight positions in the plate was filled with Millipore (Millipore, Bedford, USA) $\mathrm{H}_{2} \mathrm{O}$ for negative control (each for one TaqMan SNP genotyping probe). Genotyping was performed using Biosystems TaqMan SNP Genotyping Assay according to the manufacturer's protocol in $\mathrm{ViiA}^{\mathrm{TM}} 7$ real-time PCR system. We used SNP genotyping assays: C_11975332_10 for rs5361, C_11503414_10 for rs2066865, C_16180170_20 for rs2227589, C_8717873_10forrs1613662,C_25990131_20 for rs13146272, C_3230038_10 for rs2289252, C_11975250_10 for rs6025 and C_8726802_20 for rs1799963 (Applied Biosystems, USA). Genotypes were assigned using AutoCaller 1.1 (Applied Biosystems, USA) software. Statistical analysis was performed using Plink 1.06 software. All genotyped polymorphisms corresponded to the Hardy-Weinberg equation and the efficacy of first time SNP genotyping was $98.8 \%$. The additive inheritance model was used in logistic regression analysis and adjusted for gender, age and body mass index. Antiphospholipid IgM and $\operatorname{IgG}$, and anticardiolipin (ACA) IgM and IgG antibodies were detected using the ELISA assay (according to the manufacturer's protocol (Demeditec Diagnostics GmbH, Germany)). Statistical analysis was performed using Plink 1.06 software; Fisher's exact tests were used.

\section{Results}

In the study, we used data from patients diagnosed with CVI and analysed their association with 8 genes SNP from extracted DNA. We analysed the association of APA with the CVI stage. 
The phenotypic characteristic of the study groups are given in Tables 1 and 2 .

Commonly the patients of the study group were middle-aged women with increased BMI. When comparing the frequency of risk alleles in patient and control groups, we found a trend for the risk allele of the analysed FGG (rs20066865) gene to be found more frequently in CVI C6 ( $\mathrm{p}=0.019)$ patients Table 3.

Table 4 shows the association of the analysed SNPs in the CVI C6 group. Polymorphism of gene F11 (rs2289252) showed a significant association with CVI stage C6 (OR=1.81 $(\mathrm{p}=0.024))$. Polymorphism of genes F5 (rs6025), F2 (rs1799963), SERPINC1 (rs2227589), CYP4V2 (rs13146272), FGG (rs20066865) and GP6 (rs1613662) did not show a significant relationship with CVI C6 Table 4.

AFA were detected in $89 \mathrm{CVI}$ patients. From the 53 CVI stage C3 patients, 8 (15\%) were men and $45(85 \%)$ were women; the mean age was 46.5 years (max. 80 , min. 22 years); the BMI was 26.2 ( $\max .42 .1, \min .17 .9)$.

From the 36 CVI stage C6 patients, 9 (25\%)

\begin{tabular}{|c|c|c|}
\hline Characteristic & CVI C3 (126) & $\begin{array}{c}\text { Controls } \\
\text { (126) }\end{array}$ \\
\hline Male, n (\%) & $28(22 \%)$ & $28(22 \%)$ \\
\hline Female, n (\%) & $98(78 \%)$ & $98(78 \%)$ \\
\hline Mean age, $( \pm S D)$ years & $44.9 \pm 15.5$ & $46.3 \pm 13.1$ \\
\hline Mean BMI, $( \pm S D) \mathrm{kg} / \mathrm{m}^{2}$ & $26.2 \pm 5.9$ & $27.2 \pm 4.6$ \\
\hline
\end{tabular}

Table 2. Phenotypic characteristics of CVI C6 study group

\begin{tabular}{|c|c|c|}
\hline Characteristic & CVI C6 (62) & Controls (62) \\
\hline Male, n (\%) & $14(23 \%)$ & $14(23 \%)$ \\
\hline Female, n (\%) & 48 (77\%) & 48 (77\%) \\
\hline Mean age, $( \pm S D)$ years & $63.2 \pm 13.9$ & $61.9 \pm 11.9$ \\
\hline Mean BMI, ( \pm SD) $\mathrm{kg} / \mathrm{m}^{2}$ & $29.8 \pm 6.4$ & $30.2 \pm 5.7$ \\
\hline
\end{tabular}

were men and $27(75 \%)$ were women; the mean age was 63.4 years (max. $88, \min .33$ years); the BMI was 29.1 ( $\max .44 .2$, min. 19.9).

ACA IgM antibodies were elevated in 3 of 36 CVI stage C6 patients, ACA IgG antibodies in 5 patients, APA IgG antibodies - in 1 patient, and APA IgM antibodies - in 1 patient. Four (4) of the 53 CVI stage C3 patients had elevated ACA IgG antibodies and 2 patients had elevated APA IgG antibodies.

APA (APA IgM and IgG and ACA IgM and IgG) were elevated in 4 patients with CVI stage C3, in 7 patients with CVI stage C6. The titre of ACA IgM and IgG antibodies was not statistically significantly higher in patients with CVI stage C 6 when compared to CVI stage C 3 patients $(p=0.16$ and $p=0.11)$. The differences in the titre of APA IgM and IgG antibodies were not statistically significant in patients with CVI stage C6 when compared to CVI stage C3 patients $(\mathrm{p}=0.4$ and $\mathrm{p}=1)$. A statistically significant elevation of APA was observed in patients with CVI stage C6 when compared to patients with CVI stage C3 ( $\mathrm{p}=0.05)$.

\section{Discussion}

In this study, was explored the role of 8 SNPs previously related to the DVT conditions in 188 individuals of Latvian population and the association of APA with the CVI stage.

In our study, the polymorphism in gene F11 (rs2289252) showed a significant association with CVI stage C6 (Table 4), which corresponds to the available literature data, where patients with CVI stage C6 were found to have genetic risk factors more frequently (44-75\%) [12]. Calistru Ana M. et al found that all patients with CVI stage C6 had at least one of the DVT genetic risk factors [13]. Factor V Leiden is presented in $5 \%$ of the white population and in $7.7-36 \%$ of the CVI stage C6 $[10,12]$. The results of our study didn't show the prevalence of

\begin{tabular}{|c|c|c|c|c|c|}
\hline Table 3. Characteristics of the genotyped SNPs in CVI C6 sample group \\
\hline SNP (Gene) & Genome position & $\begin{array}{c}\text { Minor } \\
\text { allele }\end{array}$ & MAF* controls & MAF* cases & $\begin{array}{c}\text { H-W test } \\
\text { p-value }\end{array}$ \\
\hline rs6025 (F5) & 140741731 & T & 0.0081 & 0.04032 & 1 \\
\hline rs1799963 (F2) & 46466972 & A & 0.0161 & 0.03226 & 1 \\
\hline rs5361 (SELE) & 140923391 & G & 0.0887 & 0.09677 & 0.5969 \\
\hline rs2227589 (SERPINC1) & 145111334 & T & 0.1613 & 0.1452 & 0.7355 \\
\hline rs2066865 (FGG) & 151265852 & A & 0.25 & 0.2581 & 0.01876 \\
\hline rs13146272 (CYP4V2) & 182872291 & C & 0.3306 & 0.2742 & 0.6728 \\
\hline rs2289252 (F11) & 182958773 & T & 0.3952 & 0.5403 & 0.5879 \\
\hline rs1613662 (GP6) & 51859927 & G & 0.0726 & 0.121 & 0.3095 \\
\hline *MAF- Minor allele frequency & & & & & \\
\hline
\end{tabular}




\begin{tabular}{|c|c|c|c|c|c|}
\hline Table 4. Association of analysed SNPs in CVI C6 sample group \\
\hline SNP (Gene) & Genotypes & $\begin{array}{c}\text { Genotype } \\
\text { distribution } \\
\text { Cases }\end{array}$ & Controls & OR (95\% Cl)* & p- value \\
\hline rs6025 (F5) & $\pi / T C / C C$ & $0 / 5 / 57$ & $0 / 1 / 61$ & $5.542(0.6201-49.52)$ & 0.13 \\
\hline rs1799963 (F2) & AA/AG/GG & $0 / 4 / 58$ & $0 / 2 / 60$ & $2.124(0.3719-12.13)$ & 0.4 \\
\hline rs5361 (SELE) & GG/GT/T & $0 / 12 / 50$ & $0 / 11 / 51$ & $1.134(0.4469-2.878)$ & 0.79 \\
\hline rs2227589 (SERPINC1) & $\pi / T C / C C$ & $1 / 16 / 45$ & $1 / 18 / 43$ & $0.8735(0.4275-1.785)$ & 0.71 \\
\hline rs2066865 (FGG) & AA/AG/GG & $1 / 30 / 31$ & $2 / 27 / 33$ & $1.059(0.5547-2.024)$ & 0.86 \\
\hline rs13146272 (CYP4V2) & CC/CA/AA & $5 / 24 / 33$ & $5 / 31 / 26$ & $0.7624(0.4295-1.353)$ & 0.35 \\
\hline rs2289252 (F11) & T/TC/CC & $19 / 29 / 14$ & $10 / 29 / 23$ & $1.81(1.081-3.031)$ & 0.02 \\
\hline rs1613662 (GP6) & GG/GA/AA & 18204 & $0 / 9 / 53$ & $1.696(0.7262-3.962)$ & 0.22 \\
\hline${ }^{*} \mathrm{p}$ - value and OR were calculated using logistic regression adjusted for sex, age, BMI & \\
\hline
\end{tabular}

factor V Leiden (F5 rs6025) in patients with CVI stage C6, which does not match the results of Calistru Ana M. et al [10,12,20]. Prothrombin G20210A mutation is present in $2 \%$ of the white population and has been found in $0-4 \%$ of CVI stage C6 patients, in the Calistru Ana M. et al study the G20210A allele was found in 5\% of the healthy population and in $12.5 \%$ of patients with a history of DVT and was found in five of 54 CVI stage 6 patients $(9.2 \%)[10,12]$. Genetic risk factors are admitted as a risk factor for DVT, and DVT in turn is a risk factor for CVI stage C6 $[25,26]$. In the Rhoda K. et al study $41 \%$ of CVI stage C6 patients had at least one risk allele on genetic risk factor test results [26]. Munkvad and Jorgensen, Ribeauden et al., Alcaraz et al., and Hafner and Felten found that in patients with CVI stage 6, there was no difference in DVT rates between those with and without genetic risk factors, which differs from the results of our study, where there wasn't an association between V Leiden (F5 rs6025) with CVI stage 6 [26-30], but the polymorphism of gene F11 (rs2289252) showed an association with CVI stage C6.

In our study, was detected APA in 89 CVI patients was found that APA is more frequently elevated in patients with CVI stage 6. A study carried out by Alcaraz et al. in France "Leg ulcers and antiphospholipid antibodies" involved 48 patients, of which 27 patients with CVI stage C6, 9 patients had combined arterial and venous ulcers and 12 patients had arterial ulcers [31]. In this study APA were found in 22 out of 48 patients (46\%): 12 out of 27 (44\%) CVI stage C6 patients, 1 out of 9 arterial and CVI stage C6 patients and 9 out of 12 arterial ulcer patients, which coincides with the results of our study carried out in Latvia - APA in CVI stage C6 patients were elevated more frequently [31]. A hypothesis was proposed, that leukocyte stasis and activation of endothelial cells results in an immune reaction with APA, and therefore the anticoagulant therapy in CVI stage C6 patients should be discussed [31].

The results of our study performed in Latvia are similar to data from a study carried out by Mackenzie et al., where $14 \%$ of 88 patients with CVI stage C6 had elevated ACA [32,33].

Alagözlü $\mathrm{H}$ et al. carried out a study where 70 patients were analysed, of whom 35 had diabetic trophic ulcers and 35 had no ulcers - ACA were elevated in patients with ulcers [33].

The results of our study are similar to the results of the study carried out in Brazil, where data of 151 patients were analysed (81 patients with CVI stage C6, 50 with diabetic ulcers and 30 with arterial ulcers) and compared to a control group of 150 individuals without ulcers - the results demonstrated that ACA are elevated more frequently in patients with ulcers $(7.2 \% ; n=12)$ when compared to control group individuals $(1.3 \% ; n=2)$ [33]. It was found that the level of ACA IgG antibodies ranged from 10.2 to 47.9 $\mathrm{GPL} / \mathrm{ml}$, and $\mathrm{IgM}$ - from 11.2 to 65.7 $\mathrm{MPL} / \mathrm{ml}$ [33]. When comparing the patients with arterial, diabetic or venous ulcers, it was found that the level of ACA was statistically significantly higher in patients with CVI stage C6 $(p=0.02)$ and diabetic ulcers $(p=0.01)$ [33]. Hypotheses were proposed in this study, stating that ACA are elevated in patients with ulcers, probably due to a recurrent local infection, or they might already be elevated in patients with ulcers before the ulcers develop and is one of the clinical manifestations of antiphospholipid syndrome [33]. This can be important, as it might be necessary to add anticoagulants and/ or antimalarial drugs to the therapy of patients with ulcers [33].

In a study carried out in Austria, 37 CVI patients without CVI stage C2 and 54 control group patients without CVI were analysed; 
lupus anticoagulant was detected statistically significantly more frequently in CVI C2 patients when compared to control group patients $(\mathrm{p}<0.001)$ [20]. When CVI C2 patients were analysed after 4 years, it was found that patients with positive lupus anticoagulants developed CVI stage C6 more frequently than CVI C2 patients without lupus anticoagulants $(p=0.001)$ [20]. This study suggests that lupus anticoagulants might have an important role in the pathogenesis of the progression of CVI [20]. Lupus anticoagulants in patients with CVI were not analysed in our study conducted in Latvia; it is planned to continue the study and carry out the analysis of lupus anticoagulants.

\section{Conclusion}

Risk allele of FGG (rs20066865) gene was found more frequently in CVI C6 patients. The polymorphism of gene F11 (rs2289252) and positive APA showed an association with CVI stage C6.

\section{Acknowledgement}

To Baltic Vein Clinic for the opportunity to use the equipment necessary for the study. We acknowledge the Genome Database of the Latvian Population, Latvian Biomedical Research and Study Centre for providing data and DNA samples.

\section{References}

1. Nicolaides AN. Investigation of Chronic Venous Insufficiency. Circulation. 102 (20), E126-63 (2000).

2. Eklof B, Rutherford RB, Bergan JJ et al. Revision of CEAP classification for chronic venous disorders: Consensus statement. J. Vasc. Surg. 40, 1248-1252 (2004).

3. Rabe E, Pannier-Fischer F, Bromen $\mathrm{K}$ et al. Bonner Venenstudie der Deutschen Gesellschaft für Phlebologie. Phlebology. 32, 1-14 (2003).

4. MacKenzie RK, Ludlan CA, Ruckley $\mathrm{V}$ et al. The prevalence of thrombophilia in patients with chronic venous leg ulceration. J. Vasc. Surg. 49(5), 1235-1241 (2009).

5. Laing W. Chronic venous diseases of the leg. London: Office of Health Economics (1992).

6. Fowkes FGR. Epidemiology of chronic venous insufficiency. Phlebology (1996).

7. Ballard JL, Bergan JL. Chronic Venous Insufficiency, Diagnosis and Treatment. ISBN 1-85233-172-0 Springer-Verlag London Berlin Heidelberg (2012).

8. Meissner MH, Glovicki P, Bergan J et al. Primary chronic venous disorders. J. Vasc. Surg. 46, 54S-67S (2007).

9. Bradbury AW, Mackenzie RK, Burns $\mathrm{P}$ et al. Thrombophilia and chronic venous ulceration. Eur. J. Vasc. Endovasc. Surg. 24, 97-104 (2002). venous ulcer in the population of Latvia

10. Darvall KA, Sam RC, Adam DJ et al. Higher prevalence of thrombophilia in patients with varicose veins and venous ulcers than controls. J. Vasc. Surg. 49, 1235-1241 (2009).

11. White RH. The Epidemiology of Venous Thromboembolism. Circulation. 107(23), 14-8 (2003).

12. Calistru AM, Baudrier T, Goncalves L et al. Thrombophilia in venous leg ulcers: a comparative study in early and later onset. Indian. J. Dermatol. Venereol. Leprol. 78(3), 406 (2012).

13. Cumming AM, Keeney S, Salden A et al. The prothrombin gene G20210A variant: prevalence in a UK anticoagulant clinic population. Br. J. Haematol. 98, 353-355 (1997).

14. Hillarp A, Zöller B, Svensson PJ et al. The 20210 allele of the prothrombin gene is a common risk factor among Swedish outpatients with varied deep venous thrombosis. Thromb. Haemost. 78, 990-992 (1997).

15. Kapur RK, Mills LA, Spitzer SG et al. A prothrombin gene mutation is significantly associated with venous thrombosis. Arterioscler. Thromb. Vasc. Biol. 17, 28752879 (1997).

16. Mousavizadeh A, Mohammad Abadi MR, Torabi A et al. Genetic polymorphism at the growth hormone locus in Iranian Talli goats by polymerase chain reaction-single strand conformation polymorphism (PCR-SSCP). Iran. J. Biotechnol. 7, 51-53 (2009).

17. Baghizadeh A, Bahaaddini M, Mohamadabadi MR et al. Allelic Variations in Exon 2 of Caprine MHC Class II DRB3 Gene in Raeini Cashmere Goat. AmericanEurasian J. Agri. Environ. Sci. 6(4), 454-459 (2009).

18. Mohammadabadi MR, Nikbakhti M, Mirzaee HR et al. Genetic variability in three native Iranian chicken populations of the Khorasan province based on microsatellite markers. Rus. J. Genet. 46, 572-576 (2010).

19. Ruzina MN, Shtyfurko TA, Mohammadabadi MR et al. Polymorphism of the BoLA-DRB3 gene in the Mongolian, Kalmyk, and Yakut cattle breeds. Russ. J. Genet. 46, 456-463 (2010).

20. Fink AM. Lupus Anticoagulant in Patient with Chronic Venous Insufficiency. Acta. Derm. Venereol. 83, 287-289 (2003).

21. Mekkes JR. Causes, investigation and treatment of leg ulceration. Br. J. Dermatol. 148, 388-401 (2003).

22. Maréchal V, De Maistre E. Activated protein C resistance and cardiolipin antibodies in leg ulcers. Ann. Dermatol. Venereol. 127(6-7), 585-9 (2000).

23. Kelley's textbook of rheumatology. 2, 1331-1341 (2013).

24. Maessen-Visch MB, Hamulyak K, Tazelaar DJ et al. The prevalence of factor $\mathrm{V}$ Leiden mutation in patients with leg ulcers and venous insufficiency. Arch. Dermatology. 135, 41-44 (1999).

25. MacKenzie RK, Ludlan CA, Ruckley V et al. The prevalence of thrombophilia in patients with chronic venous leg ulceration. J. Vasc. Surg. 35, 718-722 (2002).

26. Browse NL, Burnard KG. The cause of venous ulceration. Lancet. 2, 243-5 (1982). 
27. Munkvad S, Jorgensen M. Resistance to activated protein C: a common anticoagulant deficiency in patients with venous leg ulceration. Br. J. Dermatology. 134, 296-298 (1996).

28. Ribeaudeau F, Senet P, Cayuela JM et al. Br. J. Dermatol. 141, 259-263 (1999).

29. Alcaraz I, Levfevre I, Wiart T et al. Leg ulcers and antiphospholipid antibodies. Prospective study of 48 cases. Annales de Dermatologie et de Venereologie. 126, 313-316 (1999).

30. Hafner J, Felten A. Resistance to activated protein C in patients with venous leg ulcers. Dermatology. 195, 413414 (1997).
31. Alcaraz I, Levfevre I, Wiart $\mathrm{T}$ et al. Leg ulcers and antiphospholipid antibodies. Prospective study of 48 cases. Annales de Dermatologie et de Venereologie. 126, 313-316 (1999).

32. Mackenzie R, Ludlam CA et al. The prevalence of thrombophilia in patients with chronic venous leg ulceration. J. Vasc. Surg. 35, 718-22 (2002).

33. Skare TL. Leg ulcers and anticardiolipin antibodies. $A n$. Bras. Dermatol. 86 (2011). 